\title{
Dental injuries in younger emergency department patients
}

\author{
Vigil James, MD*; Yona R. Vandersluis, BSc, $\mathrm{DDS}^{\dagger}$; Evangeline W. J. Zhang, HBSc, MSc*; \\ Dennis Scolnik, MB, ChB, MSc* ${ }^{*}$
}

\section{ABSTRACT}

Background: Dental trauma is a relatively common occurrence in childhood, with an impact exceeding that of periodontal diseases. It places a significant burden on the public health system because of its high frequency, impact on quality of life and consumption of resources.

Objectives: To identify changing trends of dental injury in patients between 0-18 years of age in Canada and provide a detailed assessment of dental injury patterns in patients attending a large pediatric tertiary care hospital.

Methods: This retrospective study was carried out in two parts. Firstly, data from patients who presented to the emergency departments of the 15 Canadian hospitals involved in the Injury Reporting and Prevention Program (CHIRPP) from $1^{\text {st }}$ January 1990 to $31^{\text {st }}$ December 2013 was collected. Secondly, at the Hospital for Sick Children, charts of patients identified from the aforementioned database from the years 2008, 2012 and 2015 were accessed for additional clinical data.

Results: Based on CHIRPP data there appears to be an increasing incidence in dental injuries presenting to emergency departments nationally. Participation in sports and cycling contributed to the majority of dental injuries. The use of safety equipment such as helmets with a face-grill and mouth-guard was low.

Conclusions: Our study demonstrates a rising incidence of dental injuries in young patients. Most dental injuries occurred during sports and playground related activities. The low rate of use of safety equipment and playground safety measures suggests that Canadian Standards Association standards for playgrounds could be more effective if strengthened by mandatory legislation.

\section{RÉSUMÉ}

Introduction: Les traumas dentaires sont chose relativement courante durant l'enfance, et ils ont des conséquences qui vont au-delà des parodontopathies. Ils imposent un lourd fardeau au système public de soins de santé en raison de leur fréquence élevée, de leurs répercussions sur la qualité de vie et de l'utilisation des ressources.

Objectifs: L'étude visait à cerner les changements de tendance en ce qui concerne les traumas dentaires chez les enfants de 0 à 18 ans au Canada, et à fournir une évaluation détaillée des différents types de blessures aux dents chez les patients traités dans un grand centre hospitalier de soins tertiaires pour enfants.

Méthode: II s'agit d'une étude rétrospective, menée en deux parties : tout d'abord, il y a eu collecte de données sur les patients traités dans les services des urgences des 15 hôpitaux canadiens participant au Système canadien hospitalier d'information et de recherche en prévention des traumatismes (SCHIRPT), pour la période du $1^{\mathrm{er}}$ janvier 1990 au 31 décembre 2013; ensuite, il y a eu une collecte complémentaire de données cliniques, tirées des dossiers de patients repérés dans la base de données précitée, à I'Hospital for Sick Children, pour les années 2008, 2012 et 2015.

Résultats: D'après les données recueillies dans le SCHIRPT, il semble y avoir une augmentation des cas de trauma dentaire, au service des urgences, à l'échelle nationale. La participation accrue aux activités sportives et au cyclisme explique en grande partie les blessures aux dents, tandis que le port de matériel de protection comme les casques munis d'une grille faciale et d'un protège-dents, lui, est faible.

Conclusions: Les résultats de l'étude démontrent une fréquence accrue des traumas dentaires chez les jeunes. La plupart des accidents surviennent durant les activités sportives et les activités récréatives sur les terrains de jeux. Le faible taux du port de matériel de protection et le faible degré d'application des mesures de sécurité sur les terrains de jeux donnent à penser que les normes de I'Association canadienne de normalisation pourraient être plus efficaces si elles étaient renforcées par des lois impératives.

Keywords: Canada, dental injury, trauma

From the *Division of Pediatric Emergency Medicine, Department of Pediatrics, The Hospital for Sick Children, University of Toronto, Toronto, ON; tDepartment of Dentistry, The Hospital for Sick Children, University of Toronto, Toronto, ON; and the ¥Division of Clinical Pharmacology and Toxicology, Department of Pediatrics, The Hospital for Sick Children, University of Toronto, Toronto, ON.

Correspondence to: Dr. Vigil James, Division of Pediatric Emergency Medicine, The Hospital for Sick Children, 525 University Avenue, Toronto, ON M5G 2L3; Email: vigiljames@gmail.com 


\section{INTRODUCTION}

Dental trauma is an unfortunate and relatively common occurrence in childhood, with an impact exceeding that of periodontal diseases in the young population. ${ }^{1,2}$ It places a significant burden on the public health system because of its high frequency, impact on quality of life, and consumption of resources. ${ }^{2}$ Dental trauma is defined as an impact injury to the teeth and mouth arising from any activity of daily living. ${ }^{2}$ The treatment of dental injuries should start immediately after the injury for the best outcomes, ${ }^{3}$ but seeking emergency treatment for dental injuries depends on many factors such as access to dental services, ethnic-cultural background, and affordability. ${ }^{2}$ It has been noted that more dental trauma is seen in emergency departments (ED) "after hours" because the majority of the dental offices are not accessible. ${ }^{4}$

In Canada, there is a unique opportunity for studying the clinical characteristics of injuries in children through the Canadian Hospitals Injury Reporting and Prevention Program (CHIRPP), which monitors injury patterns in patients aged $0-18$ years. Fifteen hospitals situated across the country participate in the CHIRPP injury surveillance program, which thereby helps to describe national injury patterns. Some dental injury patterns are particularly common in Canadian children, e.g., those related to widespread participation in ice hockey and baseball, ${ }^{5}$ and Canadian legislation has implemented some, mostly voluntary, strategies for injury prevention. ${ }^{6,7}$ The aim of this study was to examine changing patterns in the incidence and etiology of dental injuries in Canadian patients between 0 and 18 years of age. We also document the experience of a large tertiary care pediatric hospital to examine the use of safety equipment and describe the dental injuries.

\section{METHODS}

This retrospective study was carried out in two parts. First, data were collected from patients aged $0-18$ years who presented to the ED of CHIRPP hospitals from 1 January 1990 to 31 December 2013. Second, at the Hospital for Sick Children (SickKids), charts of patients identified from the CHIRPP database were accessed to ascertain additional clinical data from ED records and dental consultation sheets.

The CHIRPP questionnaire asks in which activity the child was involved when the injury was sustained.
We chose to assess dental injury using the three categories, cycling, sports and play (non-cycling), and nonplay, for the following reasons. Cycling involves the highest speeds and injury forces, and legislation and guidelines governing this activity were the first to be introduced. Thus, changes in incidence could be most evident in dental injuries involving this activity. The remaining activities were simply divided into non-play and "other" sports/play (non-cycling). Scooter and dirt bike injuries were included in non-cycling injuries since legislation and guidelines governing these activities were promulgated later than those involving cycling, and we were interested in trying to assess the impact of these preventive measures.

At SickKids, data were collected from all patients with dental injuries from three separate years: 2008, 2012, and 2015 , to identify changing trends and patterns in dental injuries for patients between 0 and 18 years of age. Three important documents were introduced in 2012: the Canadian Pediatric Society (CPS) position statement on preventing playground injuries, ${ }^{6}$ Canada's Active and Safe injury prevention initiative by the Public Health Agency of Canada, ${ }^{8}$ and Active and Safe for Life Physical Literacy Project by the Public Health Agency of Canada. ${ }^{9}$ Therefore, the year 2012 was chosen as the "centre point" for data collection, and the years 2008 and 2015 were used to assess changing trends in dental injuries for the four years before and after the introduction of these voluntary pieces of legislation.

This second data set was used to provide a more detailed assessment of dental injury trends. It included:

- Demographics: age, sex, and month of dental injury

- Location where the injury occurred

- Context of injury: cycling, non-cycling sports (including type), and non-play (walking, running)

- Use of safety equipment during sports

- Canadian Triage and Acuity Scale (CTAS) classification $^{10,11}$

- Previous dental care prior to arrival to the ED

- Type of injury: concussion, subluxation, extrusion, lateral luxation, intrusion, avulsion, infraction, enamel fracture, enamel-dentin fracture, enamel-dentin-pulp fracture, crown-root fracture without pulp involvement, crown-root fracture with pulp involvement, root fracture, alveolar fracture, and jaw fracture

- Presence or absence of injuries in other parts of the body (complicated dental injuries) 
- Site of dental injury: maxillary v. mandibular injury

- Type of tooth: incisor, canine, premolar, or molar; primary or secondary

- Associated injuries: alveolar, soft tissue, or bone in the mandibular, maxillary, or zygomatic areas

- Reasons for presentation to the ED: pain, bleeding, tooth mobility, temperature sensitivity

- Associated co-morbidities, e.g., obesity and seizure disorder

- Immediate adverse outcome: immediate tooth loss defined as avulsion and loss of primary or secondary tooth at the injury site or requiring dental extraction during the initial dental consultation

- Need for ED procedural sedation (for dental procedures)

Ethics approval for this study was obtained from both the institutional research ethics board and the Public Health Agency of Canada (PHAC). Data were entered into a Microsoft Excel spreadsheet (version 2016). SPSS (version 22) was used to generate descriptive data for reporting. Data are shown as number of cases and percentages.

\section{RESULTS}

The incidence and proportion of dental injuries to a total number of injuries in CHIRPP hospitals from 1 January 1990 to 31 December 2013 are shown in Figures 1 and 2.
Unless otherwise specified, the following results from SickKids are all presented with three data points, representing the years 2008, 2012, and 2015, respectively.

Most children were male $(60.7 \%, 56.4 \%$, and $57.7 \%$, respectively), and dental consultation was requested for approximately two-thirds of the patients $(60.7 \%, 73 \%$, and $61.8 \%$, respectively). Almost $60 \%$ of the dental injuries occurred in the age group of 2- to 9-year-olds (Figure 3), corresponding to a primary or mixed (primary and permanent) dentition stage of development. There was marked seasonal variation in the incidence of dental injuries, with most presenting between April and September. The majority of dental trauma occurred outdoors: 49\% in 2012 and $46 \%$ in 2015 (data not available for 2008).

Participation in sports collectively contributed to the majority of dental injuries: $65.4 \%, 52.7 \%$, and $58 \%$, respectively (Figure 4). Waterslides, gymnastics, scooters, ice hockey, street hockey, and dirt biking caused more injuries than impacts with playground equipment among the non-cycling sports-related dental injuries. Eight percent of children who sustained sportsrelated dental injuries used safety equipment such as helmets with a face grill and/or mouth-guard in 2012, and $10 \%$ did so in 2015 . Among children who actually lost a tooth, $5.3 \%$ and $3.3 \%$ were using safety equipment at the time of injury in 2012 and 2015, respectively. Subluxation, luxation, and enamel-dentin fracture were the most common dental injuries caused by cycling and non-cycling sports-related events.

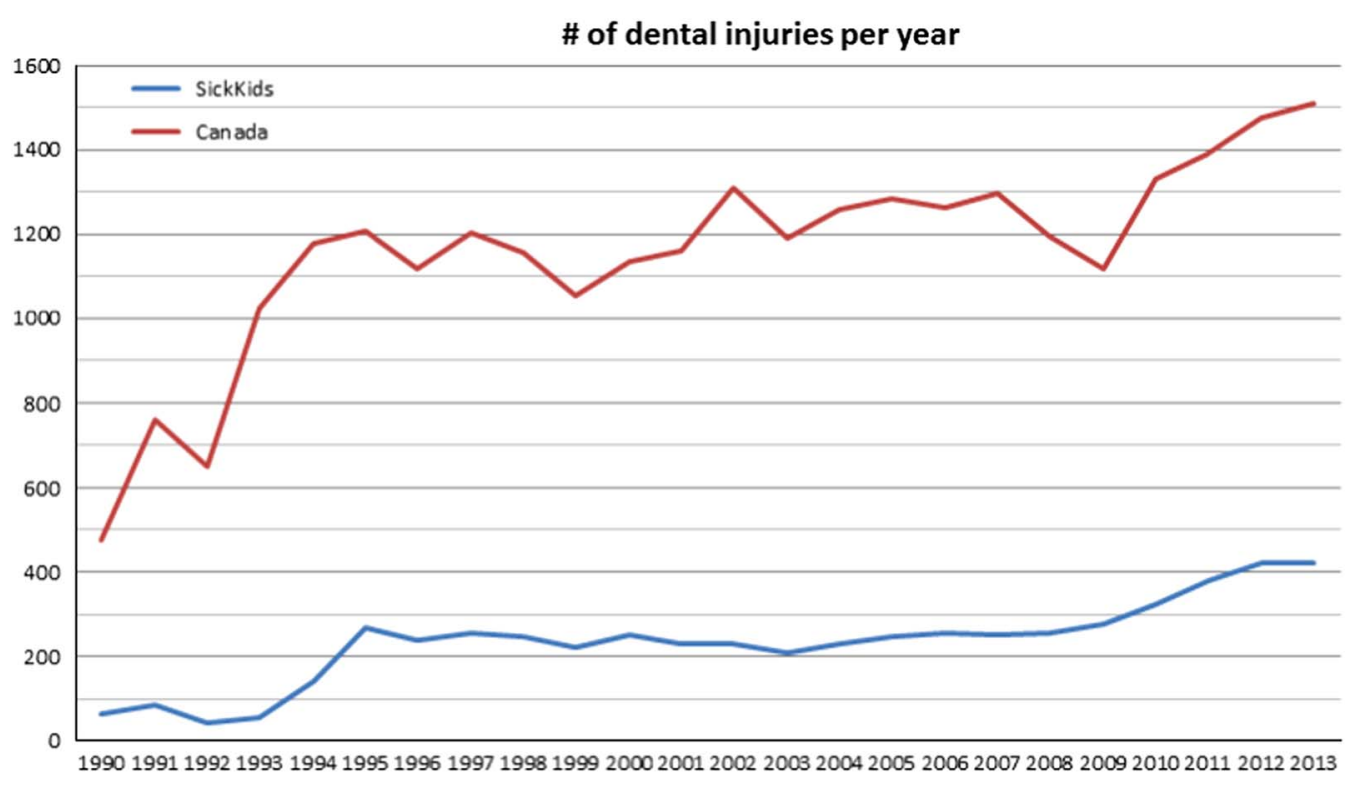

Figure 1. Annual incidence of dental injuries for SickKids and the 15 hospitals included in the CHIRPP registry 


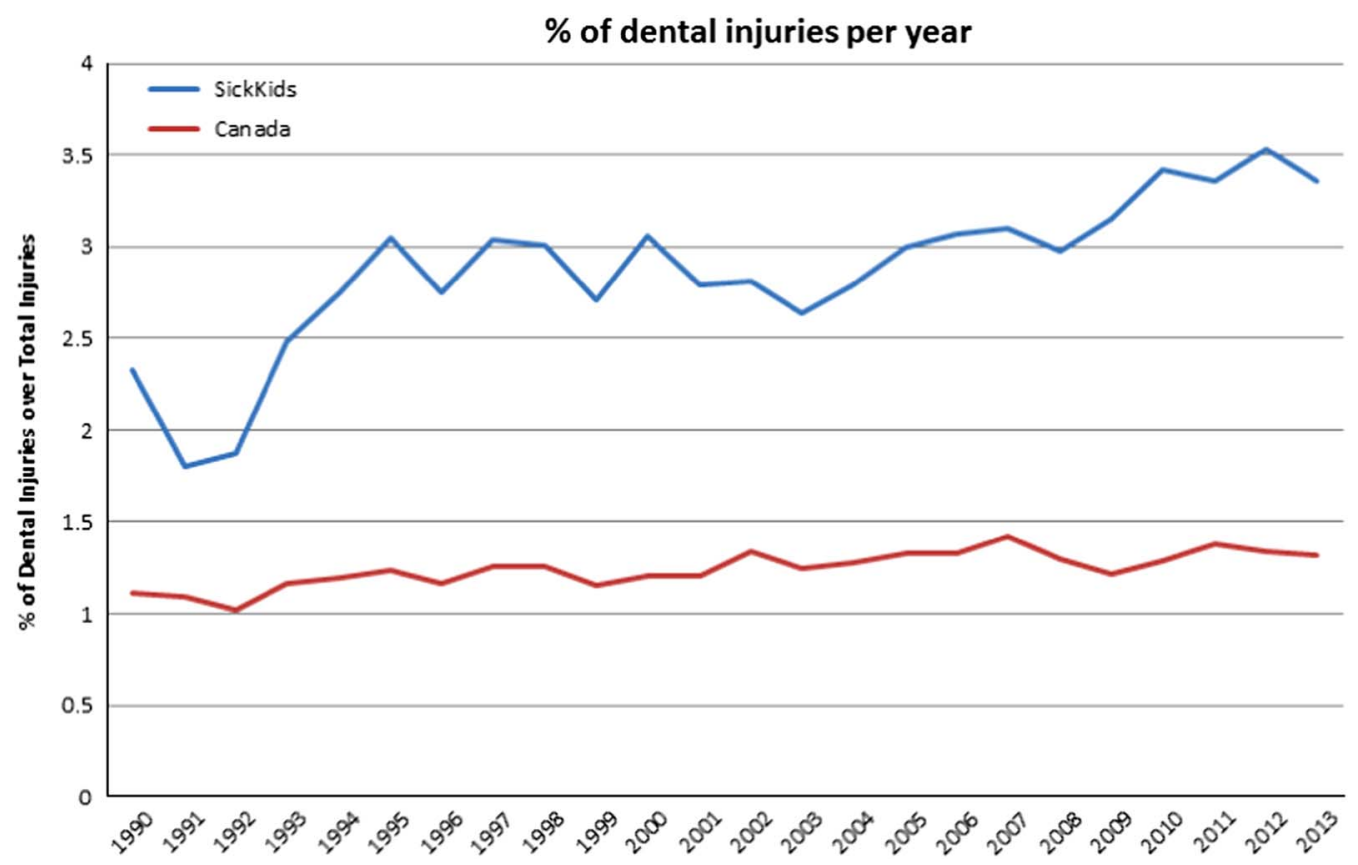

Figure 2. Annual incidence of dental injuries, as a percentage of all injuries, for SickKids and the 15 hospitals included in the CHIRPP registry

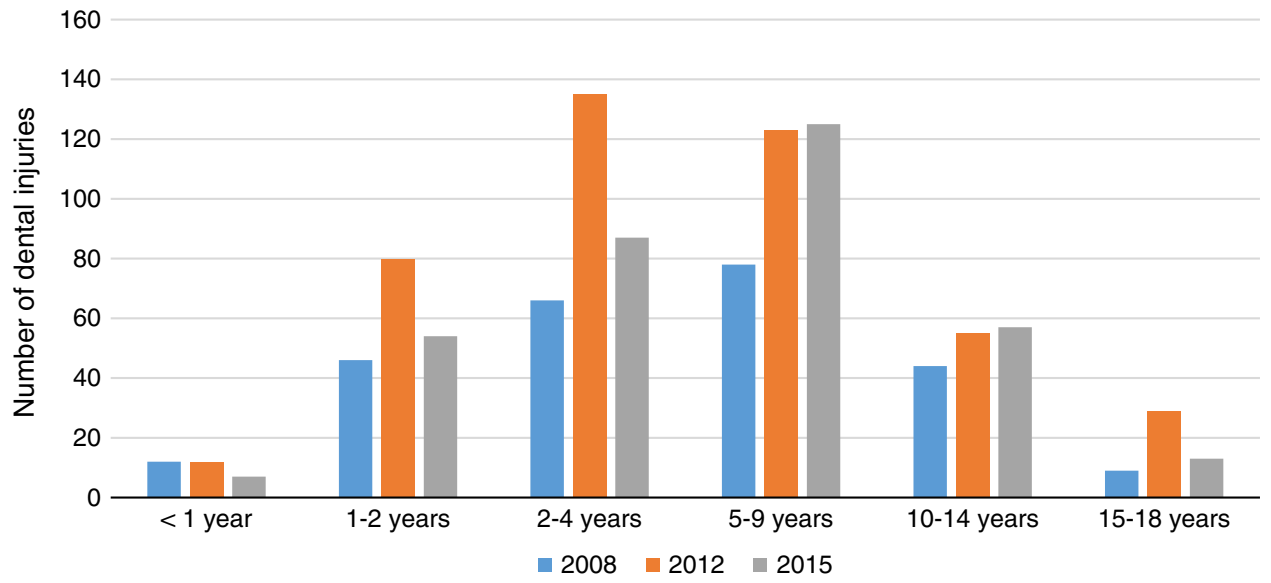

Figure 3. Age distribution of dental injuries

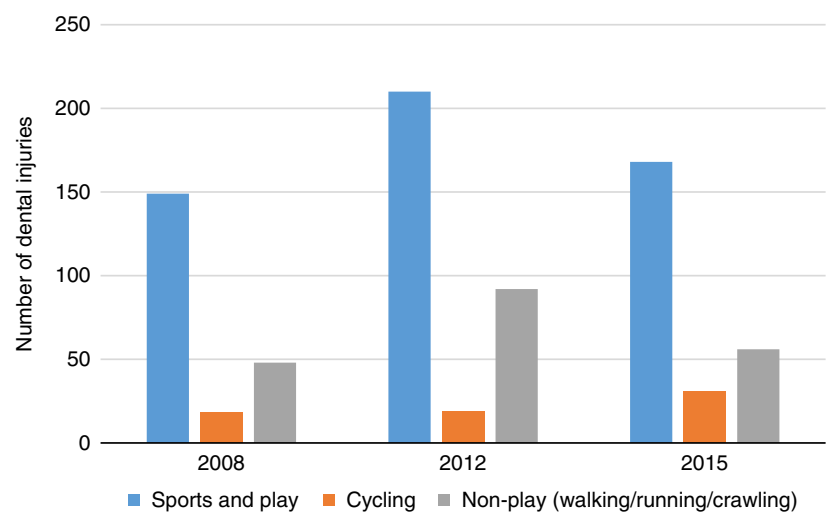

Figure 4. Activities associated with dental injuries
The majority of dental injuries were triaged under CTAS categories 3 and 4 (84.3\%, 82.7\%, and 89.2\%, respectively). Pain and bleeding were the predominant reasons children visited the $\mathrm{ED}$, with abnormal tooth mobility being the next most common reason. Dental treatment for the injury prior to arrival in the ED was low $(13.7 \%, 31.7 \%$, and $12 \%$, respectively), including among those who lost their tooth $(18 \%, 34.5 \%$, and $12.7 \%$, respectively). Complicated multisystem injuries associated with dental injuries were seen in $7.8 \%, 7.3 \%$, and $5.5 \%$, respectively, of the patients. The major comorbidity seen in children with a dental injury was a seizure disorder (5.4\%, $4.3 \%$, and $3.2 \%$, respectively). 
Dental subluxation and an enamel-dentin fracture of the crown were the most frequent type of dental injuries. Other types of injuries included intrusion, extrusion, lateral luxation, concussion, tooth avulsion, and soft tissue injuries. The maxillary central incisor tooth was injured most commonly in trauma, and injury to primary teeth predominated. Immediate tooth loss (avulsed primary tooth or secondary tooth lost at the injury site or requiring dental extraction) occurred in $35.6 \%, 26 \%$, and $43.4 \%$, respectively; of these patients, $19.7 \%, 29.2 \%$, and $12.7 \%$, respectively, experienced permanent tooth loss. Multiple follow-up appointments were required for $98.4 \%, 94.7 \%$, and $99.7 \%$, respectively, and admission for procedures and management of concurrent traumatic injuries were necessitated for $14.5 \%, 9.4 \%$, and $8.4 \%$, respectively, of the patients. Procedural sedation using ketamine, fentanyl, or midazolam was needed for $10.5 \%$, $33.1 \%$, and $12.8 \%$, respectively, of the patients.

\section{DISCUSSION}

There appears to be an increasing incidence of dental injuries presenting to EDs nationally, based on CHIRPP data. The factors that could have resulted in the increase in a number of dental injuries are multifactorial. The increase in the incidence of dental injuries is in concurrence with an upward trend for all traumaassociated injuries. ${ }^{12,13}$ Better ED triaging and reporting could have resulted in the identification of more dental injuries. Parents are more likely to bring their child to the ED might be a reflection of parents being more protective and fearful of other injuries. ${ }^{14}$ The availability of fewer dentists in the community who treat after-hour injuries could result in parents bringing their children to the ED after office hours. ${ }^{4}$ Loss of or injury to permanent teeth necessitated multiple follow-up treatments and could have a significant impact on the quality of life of patients. ${ }^{15}$ The majority of SickKids patients required specialist dental consultation for corrective dental procedures, putting considerable strain on a busy ED.

The higher rate of dental trauma among males found in our study has been noted in previous studies. ${ }^{2}$ Higher rates of trauma in males are attributed to increased risk-taking behaviour and disproportionate engagement in outdoor activity. ${ }^{16}$ The increase in dental trauma between April and September is probably due to the fact that the weather permits more outdoor activity. As noted in previous studies, ${ }^{2,17}$ most dental injuries occurred in children aged 2-9 years. This age group comprises children transitioning between primary and permanent tooth phases, meaning that the majority of injuries in this age range affect primary incisors or incompletely developed permanent incisors (root development is only completed 2-3 years posteruption). For primary teeth injuries, the most common treatment is extraction or monitoring with possible future extraction. ${ }^{18}$ Trauma to primary teeth can result in developmental sequelae to permanent teeth, with mostly qualitative and quantitative enamel defects. ${ }^{19}$ For primary teeth that are avulsed or have to be extracted, there is no known effect on speech or eating as children adapt to missing teeth. As compared with adults, if the permanent teeth are avulsed and replanted in the younger population, the prognosis is poorer as the root is less developed. ${ }^{20}$ In addition, pulp necrosis is an inevitable complication of severe trauma to permanent teeth including severe luxation or intrusions. ${ }^{2,21}$

Most dental trauma occurred in outdoor locations. Non-cycling sports and play contributed to most of the dental injuries in children, as compared with cycling and non-play activities such as walking, running, or crawling. This was in sharp contrast to previous studies in which trauma because of falls was the main etiology for dental injuries. ${ }^{2,22}$ Research has shown that playground injuries can be considerably reduced using soft, easily deepened surfaces such as sand, gravel, or synthetic surfaces in play areas to cushion falls. ${ }^{6}$ Lowering the height of the play equipment, providing protective guardrails and barriers on play equipment, and vertical rather than horizontal bars could also mitigate the effects of falls. ${ }^{6}$ Among children with sports-related dental injuries, the use of safety equipment such as helmets with face grills and mouth guards was low which argues for increased efforts to encourage the use of appropriate safety equipment during supervised sports.

Dental subluxation and enamel-dentin fracture of the crown were the most frequent types of dental injuries as have been previously reported. ${ }^{21-24}$ Other types of injuries included intrusion, extrusion, lateral luxation, concussion, tooth avulsion, and soft tissue injuries. The type of dental injury that occurs depends on the direction and magnitude of the force of the injury in addition to the patient's age, which would affect bone density and pliability, whether the tooth would move in position with an alveolar fracture, or whether the tooth itself would fracture. The maxillary central incisor tooth was the most commonly injured tooth, which could lead to significant aesthetic issues in affected children. ${ }^{25}$ 
Patients who sustained a dental injury were mostly categorized into CTAS categories 3 or 4 and were seen later than 60 minutes of arrival at the ED. CTAS scoring mandates that patients categorized as CTAS 1 and 2 be seen within 60 minutes of arrival. ${ }^{10}$ The most time-sensitive dental injury is avulsion, and minimizing extra-oral dry time can have a significant impact on the outcome. $^{26}$ An extra-oral dry time of more than five minutes leads to necrosis of periodontal ligament cells, resorption of the tooth root, and fusion of the tooth to the bone upon replantation. ${ }^{27}$ Ideally, the tooth should be replanted in less than five minutes (which means at the time/site of injury) to obtain the best outcomes. ${ }^{28}$ Changing the CTAS category of dental injuries to a higher acuity category is debatable as this would be beneficial for only avulsed teeth that are not immediately replanted and are kept wet until replantation, which should be done within 30 minutes of injury. The best strategy to improve the outcomes of avulsions would involve increasing parents' or caregivers' awareness of the need for immediate replantation of the tooth after dental trauma in case of permanent tooth injury (emphasizing that primary teeth should never be replanted). It is also important to educate parents of infants and non-verbal children who sustain orofacial trauma to look specifically for the signs of intraoral bleeding and abnormal tooth mobility and to seek medical care in case of any concern. Dental trauma coexisted with complicated multisystem injuries, emphasizing the need for health care providers, especially emergency physicians, to look specifically for dental injuries in patients with multisystem trauma, particularly those with a decreased level of consciousness.

Even though the oral region comprises only $1 \%$ of the total body surface area, it accounts for $17 \%$ of all body injuries in preschool children. ${ }^{17}$ Hence, it is both relevant and pragmatic for dentists and dental associations to educate parents about dental trauma prevention, along with advice about other dental preventive strategies, such as prevention of dental caries. The prognosis for dental injuries could be improved by concerted public education, especially regarding the avulsion of permanent teeth, because emergency management should begin at the time of injury. ${ }^{29}$ The incidence of dental injuries due to cycling showed a rising trend in 2015, as compared with 2012. Although several documents ${ }^{6,8,9}$ call for measures to lessen playground and bicycling-related injuries, these voluntary measures could be more effective if they were rigorously enforced by mandatory legislation.

\section{LIMITATIONS}

The CHIRPP database is a surveillance tool, which by its own definition does not furnish a complete set of data. It collects data only from hospital-treated patients; thus, our findings may not be representative of the real number of dental injuries. A sounder methodology would be to look at year-to-year variation and to retrieve records based on ICD-10 codes or discharge diagnosis. It would have been useful to have been able to document the time elapsed between injury and the provision of definitive dental treatment, but these data were not consistently available from patient records. Likewise, long-term outcomes of dental injuries were not available for analysis.

\section{CONCLUSIONS}

Our study demonstrated an increasing incidence of dental injuries in patients aged $0-18$ years. Most dental injuries occurred during cycling, sports, and playground-related activities. Knowledge of dental injury patterns provides a framework for preventive education by health care providers. Efforts oriented toward supervised play and cycling and the use of appropriate protective equipment would appear to be the most appropriate preventive measures. Parents, teachers, coaches, and other caregivers should be educated regarding the need to use protective equipment and to seek medical care promptly in the case of orofacial trauma resulting in dental injuries. Anticipatory guidance, on the part of dental caregivers, regarding the need for immediate reimplantation of a permanent tooth after traumatic avulsion and the need to employ safety equipment would probably be a useful strategy. A multitiered public health approach that targets education, enforcement/legislation, and engineering offers the most effective strategy for injury prevention. ${ }^{30}$ The low rate of use of safety equipment and playground safety measures suggests that the CSA standards and CPS guidelines introduced in 2012 for playground safety could be more effective if enforced by mandatory legislation.

Acknowledgements: The source of funding was the Canadian Hospitals Injury Reporting and Prevention Program (CHIRPP). The institution in which this work originated was the Hospital for Sick Children, University of Toronto, Canada. The names of the ethics boards are 1) Hospital Research Ethics Board, The 
Hospital for Sick Children, University of Toronto, Canada; and 2) Public Health Agency of Canada (PHAC) - Research Ethics Board.

Competing interests: None to disclose.

\section{REFERENCES}

1. Flores MT, Andersson L, Andreasen JO, et al. Guidelines for the management of traumatic dental injuries. II. Avulsion of permanent teeth. Dent Traumatol 2007;23(3):130-6.

2. Lam R. Epidemiology and outcomes of traumatic dental injuries: a review of the literature. Aust Dent 7 2016; 61(Suppl 1):4-20.

3. Trope M. Clinical management of the avulsed tooth. Dent Clin North Am 1995 Jan;39(1):93-112.

4. Warren M, Widmer R, Arora M, Hibbert S. After hours presentation of traumatic dental injuries to a major paediatric teaching hospital. Aust Dent 7 2014;59(2):172-9.

5. Public Health Agency of Canada. Emergency department surveillance of injuries and head injuries associated with baseball, football, soccer and ice hockey, children and youth, ages 5 to 18 years, 2004 to 2014. Health Promotion and Chronic Disease Prevention in Canada: Research, Policy and Practice - Public Health Agency of Canada; 2016. Available at: http://www.phac-aspc.gc.ca/publicat/hpcdppspmc/36-1/ar-03-eng.php (accessed September 3, 2016).

6. Fuselli P, Yanchar NL, Canadian Paediatric Society, Injury Prevention Committee. Preventing playground injuries; 2012. Available at: http://www.cps.ca/documents/position/ playground-injuries (accessed June 20, 2016).

7. Parachute. Playground standards in Canada. Available at: http://www.parachutecanada.org/injury-topics/item/playgroundstandards-in-canada-lt (accessed June 26, 2016).

8. Public Health Agency of Canada. Fact Sheet - Funding to Support Active and Safe Participation in Sports and Recreation - Public Health Agency of Canada; 2012. Available at: http://www.phac-aspc.gc.ca/inj-bles/2012_ 0829-fs-fi-eng.php (accessed January 29, 2017).

9. Public Health Agency of Canada. Fact Sheet - Funding to Active and Safe for Life - Physical Literacy - Public Health Agency of Canada; 2012. Available at: http://www.phac-aspc. gc.ca/inj-bles/2012_0828-fs-fi-eng.php (accessed January 29, 2017).

10. Gouin S, Gravel J, Amre DK, Bergeron S. Evaluation of the Paediatric Canadian Triage and Acuity Scale in a pediatric ED. Am 7 Emerg Med 2005;23(3):243-7.

11. Yates MT, Ishikawa T, Schneeberg A, Brussoni M. Pediatric Canadian Triage and Acuity Scale (PaedsCTAS) as a Measure of Injury Severity. Int 7 Environ Res Public Health 2016;13(7):E659.

12. Statistics Canada. Injuries in Canada: Insights from the Canadian Community Health Survey. Available at: http://www.statcan.gc.ca/pub/82-624-x/2011001/article/11506eng.htm (accessed August 21, 2016).
13. Government of Canada PHA of C. Facts on Injury; 2003. Available at: http://www.phac-aspc.gc.ca/injury-bles/factseng.php (accessed August 21, 2016).

14. Farion KJ, Wright $M$, Zemek R, et al. Understanding low-acuity visits to the pediatric emergency department. PLoS One 2015;10(6):e0128927.

15. Aldrigui JM, Abanto J, Carvalho TS, et al. Impact of traumatic dental injuries and malocclusions on quality of life of young children. Health Qual Life Outcomes 2011;9(1):78.

16. Zaleckiene V, Peciuliene V, Brukiene V, Drukteinis S. Traumatic dental injuries: etiology, prevalence and possible outcomes. Stomatolologija 2014;16(1):7-14.

17. Andersson L. Epidemiology of traumatic dental injuries. 7 Endod 2013;39(3 Suppl):S2-5.

18. Arikan V, Sari S, Sonmez H. The prevalence and treatment outcomes of primary tooth injuries. Eur $\mathcal{F}$ Dent 2010; 4(4):447-53.

19. de Amorim LF, Estrela C, da Costa LR. Effects of traumatic dental injuries to primary teeth on permanent teetha clinical follow-up study. Dent Traumatol 2011;27(2):117-21.

20. Andreasen FM, Zhijie Y, Thomsen BL. Relationship between pulp dimensions and development of pulp necrosis after luxation injuries in the permanent dentition. Endod Dent Traumatol 1986;2(3):90-8.

21. Andreasen JO. Luxation of permanent teeth due to trauma. A clinical and radiographic follow-up study of 189 injured teeth. Scand 7 Dent Res 1970;78(3):273-86.

22. Atabek D, Alaçam A, Aydintuğ I, Konakoğlu G. A retrospective study of traumatic dental injuries. Dent Traumatol 2014; 30(2):154-61.

23. Traebert J, Peres MA, Blank V, Böell RS, Pietruza JA. Prevalence of traumatic dental injury and associated factors among 12-year-old school children in Florianópolis, Brazil. Dent Traumatol 2003;19(1):15-8.

24. Altun C, Ozen B, Esenlik E, Guven G, et al. Traumatic injuries to permanent teeth in Turkish children, Ankara. Dent Traumatol 2009;25(3):309-13.

25. Bryan RA, Welbury RR. Treatment of aesthetic problems in paediatric dentistry. Dent Update 2003;30(6):307-13.

26. Barrett EJ, Kenny DJ. Survival of avulsed permanent maxillary incisors in children following delayed replantation. Endod Dent Traumatol 1997;13(6):269-75.

27. Andreasen JO, Borum MK, Jacobsen HL, Andreasen FM. Replantation of 400 avulsed permanent incisors. 4. Factors related to periodontal ligament healing. Endod Dent Traumatol 1995;11(2):76-89.

28. Kenny DJ, Casas MJ. The Field-Side Guide to Dental Injuries - Denti-Pro Blog. Available at: http://articles.denti-pro. com/index.php/2016/01/06/the-field-side-guide-to-dentalinjuries/ (accessed September 4, 2016).

29. Levin L, Zadik Y. Education on and prevention of dental trauma: it's time to act! Dent Traumatol 2012;28(1):49-54.

30. Yanchar NL, Warda LJ, Fuselli P. Child and youth injury prevention: A public health approach. Paediatr Child Health 2012;17(9):511-2. 